\title{
DEGENERATIVE SCOLIOSIS: A CASE REPORT
}

\author{
I Ketut Martiana ${ }^{1}$, M Mukaddam Alaydrus ${ }^{2 *}$ \\ ${ }^{1}$ Staff of Orthopaedic and Traumatology Department, Faculty of Medicine, Universitas \\ Airlangga, Dr Soetomo General Hospital, Surabaya \\ ${ }^{2}$ Resident of Orthopaedic and Traumatology Department, Faculty of Medicine, Universitas \\ Airlangga, Dr Soetomo General Hospital, Surabaya \\ *Corresponding Author: M Mukaddam Alaydrus, Resident of Orthopaedic and Traumatology \\ Department, Faculty of Medicine, Universitas Airlangga, Jl. Mayjen Prof. Dr. Moestopo 6-8, \\ Surabaya \\ E-mail: adam_basketman@yahoo.com
}

\begin{abstract}
ABSTRAK
Latar belakang: Skoliosis pada orang dewasa adalah kelainan bentuk tulang belakang pada pasien dewasa dengan sudut Cobb lebih dari $10^{\circ}$ pada bidang koronal. Skoliosis degeneratif adalah istilah yang digunakan untuk adanya deviasi koronal tulang belakang pada populasi lanjut usia akibat degenerasi segmen. Laporan kasus ini memaparkan pilihan tata laksana yang cukup berbeda yaitu menerapkan koreksi vertebra intraoperatif pada pasien. Tata laksana operatif yang dilaksanakan pada subjek telah mengalami keberhasilan yang ditunjukkan dengan adanya perbaikan gejala dan progesifitas kurva pada pasien.

Kasus: Seorang pasien mengalami skoliosis degeneratif di RS RKZ Surabaya. Data diambil dari rekam medis, catatan klinis pasien, kunjungan rumah, dan pemeriksaan fisik pada pasien. Diskusi: Dari hasil pemeriksaan klinis pascaoperasi didapatkan bahwa keluhan nyeri membaik dibandingkan keluhan pre op. Dari hasil pemeriksaan radiologis post op didapatkan kedudukan fiksasi baik, tak tampak spondylolisthesis, lumbar dextroscoliosis (+), lumbar spondylosis (+), tip drain setinggi Th12-L1.
\end{abstract}

Kesimpulan: Pemberian tatalaksana operatif secara langsung dapat memperbaiki kualitas hidup pasien dan mengurangi gejala yang dialami dalam waktu yang lebih singkat.

Keywords: skoliosis degeneratif, sudut Cobb, tatalaksana operatif

\begin{abstract}
Background: Scoliosis in adults is a spinal deformity in adult patients with a Cobb angle of more than $10^{\circ}$ in the coronal plane. Degenerative scoliosis is a term used for the presence of spinal coronal deviation in the elderly population due to segment degeneration. This case report presents a quite different management option, namely applying intraoperative vertebral correction to the subject. The operative procedure carried out on the patient has experienced success as indicated by improvement in symptoms and curve progressiveness in patients.

Case: A patient suffers degenerative scoliosis at Surabaya RKZ Hospital. Data is taken from medical records, patient clinical records, home visits, and physical examination of patients.

Discussion: From the results of the post op clinical examination, it was found that pain complaints improved compared to pre-op complaints. From the results of the post op radiological examination, the position of fixation was good, there was no spondylolisthesis, lumbar dextroscoliosis (+), lumbar spondylosis (+), drain tip as high as Th12-L1.

Conclusion: Giving operative management can directly improve the patient's quality of life and reduce symptoms experienced in a shorter time.
\end{abstract}

Keywords: Degenerative scoliosis, Cobb angle, operative management 


\section{PENDAHULUAN}

Skoliosis dibagi menjadi 2 tipe, yaitu struktural dan non struktural. Skoliosis tipe non struktural antara lain skoliosis postural, histerikal, skiatik, inflamatori, dan kompensatori. Beberapa diantaranya dapat berkembang menjadi skoliosis struktural. Skoliosis pada orang dewasa adalah kelainan bentuk tulang belakang pada pasien dewasa dengan sudut Cobb lebih dari $10^{\circ}$ pada bidang koronal. ${ }^{1-4}$

Skoliosis degeneratif adalah istilah yang digunakan untuk adanya deviasi koronal tulang belakang pada populasi lanjut usia akibat degenerasi segmen. Skoliosis degeneratif perlu dibedakan dari skoliosis dewasa karena skoliosis degeneratif merupakan hasil dari degenerasi progresif elemen-elemen tulang belakang struktural yang mengarah pada gangguan alignment tulang belakang, sedangkan skoliosis dewasa adalah istilah kolektif (termasuk skoliosis degeneratif) yang terdiri dari semua deformitas tulang belakang pada individu yang memiliki rangka tulang yang sudah matur. ${ }^{1}$

Skoliosis degeneratif memiliki angka insidensi yang bervariasi dari 1-10\%. Sekitar $30 \%$ dari pasien yang mengalami skoliosis degeneratif, tidak memiliki riwayat abnormalitas spinal sebelumnya. Pada umumnya skoliosis degeneratif terdiagnosis pada usia 40 tahun tanpa adanya riwayat skoliosis idiopatik dewasa (AIS). ${ }^{2}$ Prevalensi skoliosis degeneratif meningkat seiring dengan peningkatan usia, dan hanya sedikit yang bersifat simptomatik. ${ }^{5}$

Pasien asimptomatik tidak membutuhkan terapi, namun tindak lanjut tetap direkomendasikan untuk memantau progresivitas kurva. Apabila gejala muncul, maka pasien dianjurkan menggunakan beberapa modalitas pengobatan non-operatif dengan peninjauan yang cermat mengenai hasilnya. Intervensi non operatif, sering dipilih secara empiris, seperti agen farmakologis, terapi fisik dan latihan, terapi akuatik, manipulasi chiropraktik, dan yoga adalah pilihan pertama pengobatan yang ditentukan oleh dokter perawatan primer, tetapi dalam literatur belum terbukti memiliki efikasi jangka panjang pada orang dewasa dengan skoliosis. ${ }^{1,6}$

\section{LAPORAN KASUS}

Pasien perempuan berusia 67 tahun mengeluhkan nyeri pada punggung bawah. Nyeri pada punggung bawah dirasakan sejak 1 tahun yang lalu. Nyeri dirasakan pada punggung bawah seperti tersetrum dan tidak menjalar. Pasien mengeluhkan sulit berjalan akibat nyeri pada punggung tersebut. Tidak ada riwayat trauma sebelumnya. Tidak ada riwayat keluhan pada punggung ataupun tulang belakang bengkok sejak lahir. 
Pada pemeriksaan fisik didapatkan tekanan darah 130/80 $\mathrm{mmHg}$, nadi $80 \mathrm{x} / \mathrm{menit}$, suhu tubuh $36,6^{\circ} \mathrm{C}$. Pada pemeriksaan status generalis didapatkan hasil dalam batas normal. Status lokalis regio lumbal, didapatkan scar pasca operasi, tidak ada nyeri tekan, dan ROM bebas (Gambar 1).

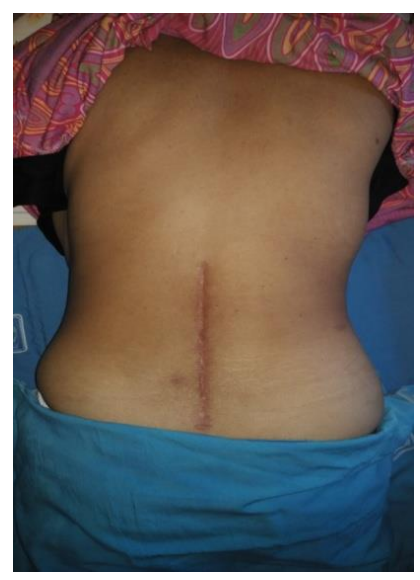

Gambar 1. Foto Klinis Regio Lumbal

Pemeriksaan radiologis pre operatif dilakukan dengan foto polos lumbosacral AP dan lateral pada tanggal 10 Agustus 2018 dan didapatkan hasil baca spondylosis, thoracolumbar dextroscoliosis, paralumbar muscle spasm (Gambar 2). Selain itu, dilakukan juga evaluasi foto radiologis thorax PA pada tanggal 10 Agustus 2018 dengan hasil baca thoracolumbar dextroscoliosis (Gambar 3).
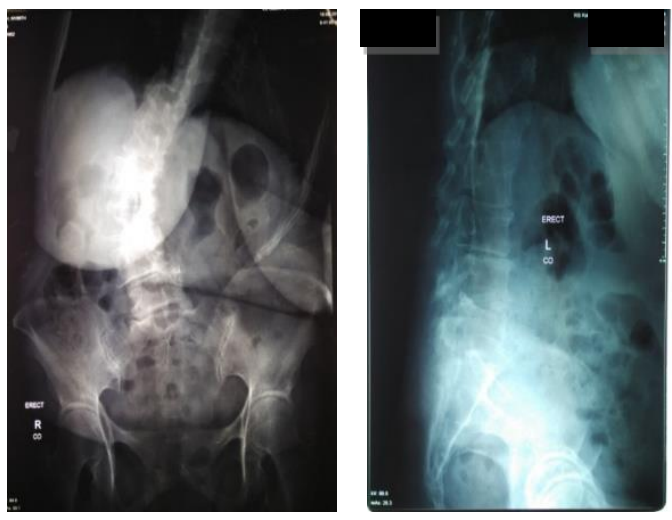

Gambar 2. Foto Polos Lumbosacral AP dan lateral

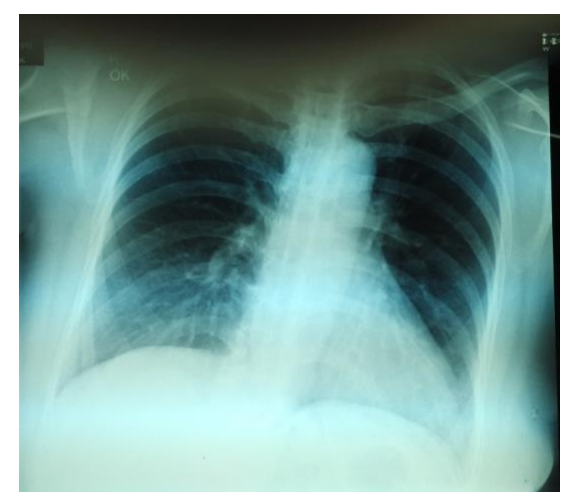

Gambar 3. Foto Thorax PA

Selanjutnya dilakukan pemeriksaan MRI lumbal non-contrast axial T1, T2 \& sagittal T1,T2 pada tanggal 12 September 2018 didapatkan hasil anterior spondylolisthesis L4-5 $\pm 15 \%$, lumbar dextroscoliosis. Degenerative lumbar disc disease: L3-4: right foraminal disk protrusion menyebabkan mild right foraminal stenosis, L4-5: Left foraminal disk extrusion menyebabkan severe left foraminal stenosis, L5-S1: Right paramedial disk protrusion menyebabkan mild right paramedial canal stenosis (Gambar 4). 
Laporan Kasus

Vol 8 No. 2, Oktober 2019

ISSN 2460-8742

http://journal.unair.ac.id/ORTHO@journal-orthopaedi-and-traumatology-surabaya-media-104.html

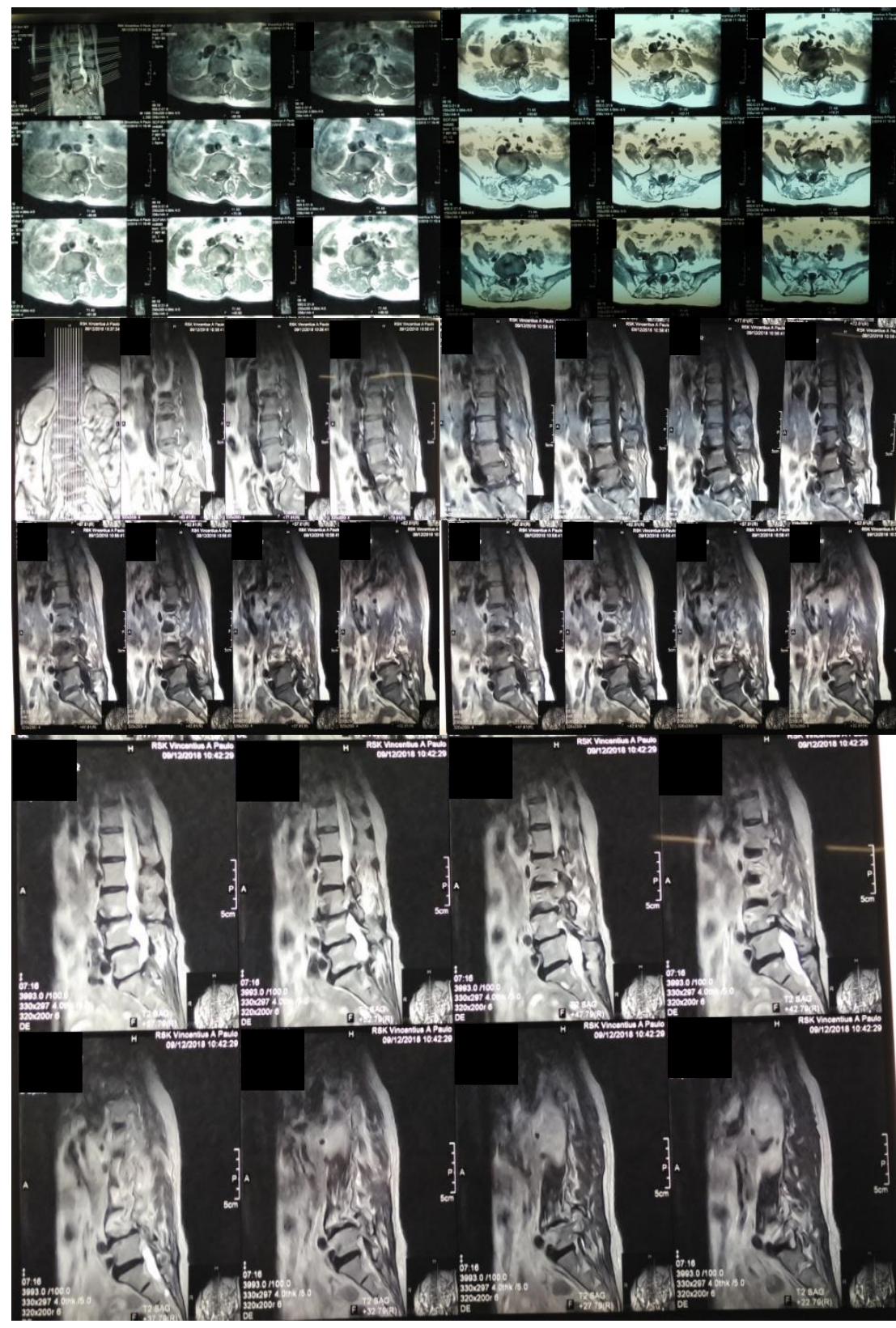

Gambar 4. MRI lumbal non kontras

Pascaoperasi, pasien dilakukan evaluasi foto radiologis lumbosacral AP Lateral pada tanggal 16 Oktober 2018. Didapatkan hasil baca kedudukan fixatie baik, tak tampak spondylolisthesis, lumbar dextroscoliosis (+), lumbar spondylosis (+), tip drain setinggi Th12-L1 (Gambar 5). 


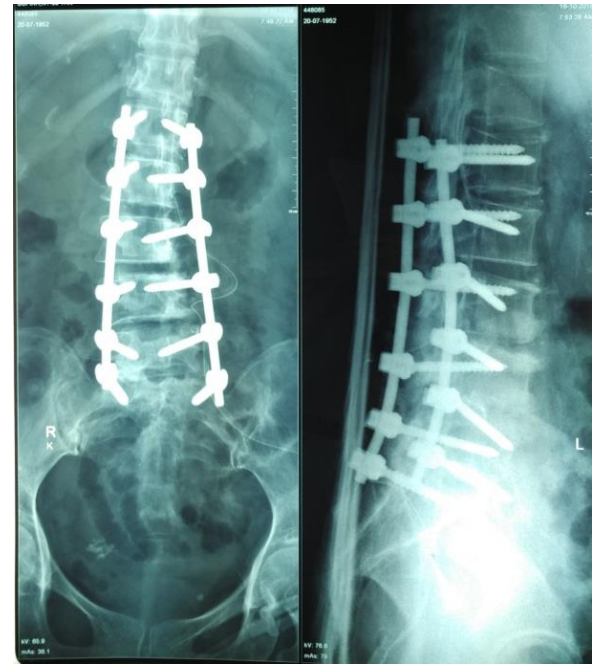

Gambar 5. Foto Lumbosacral AP/ Lateral Post operatif

$\begin{array}{rrr}\text { Setelah } & \text { menjalani } & \text { serangkaian } \\ \text { pemeriksaan } & \text { dilanjutkan } & \text { dengan }\end{array}$
pemeriksaan MRI maka diagnosis kasus tersebut dinyatakan sebagai skoliosis degeneratif. Kemudian dilakukan tatalaksana berupa koreksi skoliosis pada tanggal 15 Oktober 2018.

\section{DISKUSI}

Skoliosis degeneratif biasanya didiagnosis pada pasien berusia lebih dari 40 tahun, dengan rerata usia 70,5 tahun. Skoliosis degenerative ditandai dengan kurva lumbal $>10^{\circ}$ yang disertai kurva fraksional distal. ${ }^{7}$

Salah satu penyebab yang diduga menjadi penyebab skoliosis degeneratif adalah osteoporosis. Bridwell mengevaluasi 48 pasien dengan skoliosis de novo yang berusia 40-80 tahun, mayoritas pasien (32 pasien) berjenis kelamin perempuan dan 38 pasien diketahui mengalami osteopenik, sehingga disimpulkan bahwa osteoporosis sebagai etiologi signifikan. Namun, penelitian lain mendapatkan bahwa tidak ada korelasi langsung antara osteoporosis dengan skoliosis degenratif, dimana pada studi itu angka kejadian pada laki-laki dan perempuan sama. Perubahan degeneratif asimetris pada diskus, kompresi korpus vertebra, dan arthritis sendi facet merupakan penyebab predominan skoliosis degeneratif, dengan degenerasi diskus sebagai penyebab awal. $^{4,8}$

Dari anamnesis, pemeriksaan fisik, dan pemeriksaan penunjang ditegakkan diagnosis dari kasus ini adalah skoliosis degeneratif. Pemilihan tata laksana yang tepat untuk Adult Degenerative Scoliosis cukup rumit karena kondisinya heterogen dengan gejala yang beragam, dan hasil tata laksananya yang bervariasi. ${ }^{3}$ Umumnya adanya penyakit penyerta dapat mempengaruhi pemilihan terapi dan hasil terapi. ${ }^{9}$ Dewasa ini, hanya ada sedikit bukti bahwa tatalaksana konservatif pada Adult Degenerative Scoliosis efektif dalam meningkatkan kualitas hidup atau gejala terkait. Manajemen non operatif dapat dilakukan pada pasien yang tidak ada gejala signifikan stenosis, radicular, dan/atau nyeri punggung termasuk kurva $<30^{\circ}$ dengan 
subluksasi $<2 \quad \mathrm{~mm}$ dengan osteofit anterior. $^{3,10}$

Indikasi umum operasi pada pasien dengan skoliosis degeneratif adalah gejala radiks saraf dan stenosis spinal. Pilihan pengobatan spesifik ditawarkan ketika korelasi terjadi antara temuan radiografi klinis dan spesifik, khususnya, angulasi endplate L-3 dan L-4, lordosis lumbar, kifosis torakolumbar, dan listesis lateral. Kurva lumbar dengan listesis $>30-40^{\circ}$ dan/atau $6 \mathrm{~mm}$ juga dipertimbangkan untuk intervensi operatif. Selain itu, perkembangan kurva serta defisit neurologis progresif adalah indikator untuk intervensi bedah. Pasien yang lekuknya berkembang lebih dari $10^{\circ}$ dan/atau memiliki peningkatan subluksasi $>3 \mathrm{~mm}$ dengan peningkatan gejala klinis dipertimbangkan untuk melakukan terapi pembedahan. ${ }^{11-13}$

Pada laporan kasus ini telah dilakukan tata laksana operatif tanpa melakukan tata laksana non operatif terlebih dahulu. Pemberian tata laksana operatif secara langsung dapat memperbaiki kualitas hidup pasien dan mengurangi gejala yang dialami dalam waktu yang lebih singkat. ${ }^{4}$

Sama halnya dengan komplikasi operasi yang dilakukan pada tulang belakang lainnya, komplikasi yang dapat terjadi pada operasi rekontruksi skoliosis degeneratif diantaranya adalah robekan dura, kehilangan darah yang memerlukan transfusi, cedera neurologis, dan kematian. Usia pasien merupakan salah satu faktor yang berperan. Insidensi lebih tinggi pada kasus dengan deformitas yang lebih berat dan kasus revisi. Pasien komorbid seperti diabetes, merokok, penggunaan steroid juga dapat meningkatkan risiko. Jika terjadi, robekan harus ditatalaksana dengan perbaikan primer dan didukung dengan perekan, kolagen matriks atau graf otot/lemak. ${ }^{14}$ Meskipun risiko komplikasi yang tinggi pada pasien yang menjalani operasi rekonstruktif untuk Adult Degenerative Scoliosis, sebagian besar studi menunjukkan peningkatan yang signifikan dalam kualitas hidup dan tingkat kepuasan pasien yang tinggi. ${ }^{4}$ Penelitian yang dilakukan oleh Kluba et al (2008) membandingkan tatalaksana operatif dan konservatif pada pasien dengan skoliosis degeneratif. Hasilnya menunjukkan bahwa pada pasien yang dilakukan terapi operatif menunjukkan sedikit komplikasi dan perbaikan signifikan pada kemampuan berjalan dan berkurangnya kebutuhan penggunaan analgetik. ${ }^{15}$ Tata laksana operatif yang dilaksanakan pada kasus ini telah mengalami keberhasilan yang ditunjukkan dengan adanya perbaikan gejala dan progesivitas kurva pada pasien.

\section{KESIMPULAN DAN SARAN}

Skoliosis degeneratif adalah istilah yang digunakan untuk adanya deviasi 
koronal tulang belakang pada populasi lanjut usia akibat degenerasi segmen. Pemilihan tata laksana yang tepat untuk Adult Degenerative Scoliosis cukup rumit karena kondisinya heterogen dengan gejala yang beragam dan hasil tata laksananya yang bervariasi. Pada laporan kasus ini telah dilakukan tata laksana operatif tanpa melakukan tata laksana non operatif terlebih dahulu. Pemberian tata laksana operatif secara langsung pada pasien bertujuan untuk memperbaiki kualitas hidup pasien dan mengurangi gejala yang dialami dalam waktu yang lebih singkat. Secara umum, saat ini pemilihan tata laksana untuk skoliosis degeneratif lebih condong ke arah tata laksana non operatif, meskipun begitu pada beberapa laporan kasus dan penelitian pemberian tata laksana operatif secara langsung telah memberikan hasil yang baik dan dapat memerbaiki kualitas hidup pasien secara lebih cepat dan signifikan. Penulis berharap banyak penelitian dan laporan kasus yang membahas mengenai hal ini, terutama mengenai dampak jangka panjang yang terjadi pasca terapi.

\section{REFERENSI}

1. Kotwal S, Pumberger M, Hughes A, Girardi F. Degenerative Scoliosis: A Review. HSS J. 2011 Oct 11;7(3):25764.

2. Silva FE, Lenke LG. Adult degenerative scoliosis: evaluation and management. Neurosurg Focus. 2010; 28:E1.
3. Graham RB, Sugrue PA, Koski TR. Adult Degenerative Scoliosis. Clin Spine Surg. 2016; 29(3):95-107.

4. Kebaish KM. Degenerative (De Novo) Adult Scoliosis. Semin Spine Surg. 2009;21(1):7-15.

5. Silvestre MD, Lolli F, Greggi T, et al. Adult's Degenerative Scoliosis: Midterm Results of Dynamic Stabilization without Fusion in Eldery Patients- Is it Effective?Advances in Orthopedics. 2013; 7:1-8.

6. Tambe AD, Michael ALR. (iii) Adult degenerative scoliosis. Orthop Trauma. 2011;25(6):413-24.

7. York PJ, Kim HJ. Degenerative Scoliosis. Curr Rev Musculoskelet Med. 2017;10(4):547-58.

8. Cho K, Kim Y, Shin S, Suk S. Surgical Treatment of Adult Degenerative Scoliosis. Asian Spine J. 2014;8(3):371.

9. Palmisani M, Dema E, Cervellati S. Surgical Treatment of Adult Degenerative Scoliosis. European Spine Journal. 2013; 22(6):829-833.

10. Birkness JK, White AP, Albert TJ, Shaffrey TI, Harrop JS. Adult Degenerative Scoliosis: A Review. Neurosurgery Journal. 2008: 63(3):94103.

11. Koerner JD, Reitman CA, Arnold PM, Rihn J. Degenerative Lumbar Scoliosis. JBJS Rev. 2015;3(4):1.

12. Shridharani SM, Munroe BA, Hood KA. Complications in adult degenerative scoliosis surgery. Semin Spine Surg. 2017;29(2):118-22.

13. Koerner JD, Reitman CA, Arnold PM, Rihn J. Degenerative Lumbar Scoliosis. JBJS Reviews. 2015;3(4):1-10.

14. Shridharani SM, Munroe BA, Hood KA. Complications in adult degenerative scoliosis surgery. Semin Spine Surg. 2017:1-5.

15. Kluba T, Dikmenli G, Dietz K, Giehl JP, Niemeyer T. Comparison of Surgical and Conservative Treatment for Degenerative Lumbar Scoliosis. Archipelago Orthopedy Trauma Surgery. 2009: 129: 1-5. 